\title{
Comparative mapping reveals quantitative trait loci that affect spawning time in coho salmon (Oncorhynchus kisutch)
}

\author{
Cristian Araneda ${ }^{1}$, Nelson F. Díaz ${ }^{1}$, Gilda Gomez ${ }^{1}$, María Eugenia López ${ }^{1}$ and Patricia Iturra ${ }^{2}$ \\ ${ }^{1}$ Departamento de Producción Animal, Facultad de Ciencias Agronómicas, Universidad de Chile, \\ La Pintana, Región Metropolitana, Santiago, Chile. \\ ${ }^{2}$ Programa de Genética Humana, Instituto de Ciencias Biomédicas, Facultad de Medicina, \\ Universidad de Chile, Independencia, Región Metropolitana, Santiago, Chile.
}

\begin{abstract}
Spawning time in salmonids is a sex-limited quantitative trait that can be modified by selection. In rainbow trout (Oncorhynchus mykiss), various quantitative trait loci (QTL) that affect the expression of this trait have been discovered. In this study, we describe four microsatellite loci associated with two possible spawning time QTL regions in coho salmon (Oncorhynchus kisutch). The four loci were identified in females from two populations (early and late spawners) produced by divergent selection from the same base population. Three of the loci (OmyFGT34TUF, One2ASC and One19ASC) that were strongly associated with spawning time in coho salmon $(p<0.0002)$ were previously associated with QTL for the same trait in rainbow trout; a fourth loci (Oki10) with a suggestive association $(p=0.00035)$ mapped $10 \mathrm{cM}$ from locus OmyFGT34TUF in rainbow trout. The changes in allelic frequency observed after three generations of selection were greater than expected because of genetic drift. This work shows that comparing information from closely-related species is a valid strategy for identifying QTLs for marker-assisted selection in species whose genomes are poorly characterized or lack a saturated genetic map.
\end{abstract}

Key words: coho salmon, QTL, spawning time.

Received: September 23, 2011; Accepted: January 5, 2012.

\section{Introduction}

Spawning time in salmonids is an important sexlimited life-history trait that determines fertilization and progeny emergence dates and also affects the probability of survival and growth rate of small fry (Quinn et al., 2002). An increase in the reproductive period in salmon farming allows better management of fish production (to account for seasonal variations) and increases the period during which eggs are available on the market (Gall and Neira, 2004).

Spawning time for rainbow trout (Oncorhynchus mykiss) shows highly additive genetic variation $\left(0.53 \leq \mathrm{h}^{2} \leq\right.$ 0.65) (Siitonen and Gall, 1989; Su et al., 1999). Current evidence supports a polygenic inheritance for spawning time with several quantitative trait loci (QTL) affecting this trait (Sakamoto et al., 1999; Fishback et al., 2000; O’Malley et al., 2003; Leder et al., 2006).

In coho salmon (Oncorhynchus kisutch), it is possible to shift the spawning time of cultivated populations (Quinn et al., 2002). Estimates of heritability in cultivated popula-

Send correspondence to Cristian Araneda. Departamento de Produccion Animal, Facultad de Ciencias Agronómicas, Universidad de Chile, Adva. Santa Rosa 11315, La Pintana 8820808, Santiago, Chile. E-mail: craraned@uchile.cl. tions from Chile range from $0.24 \pm 0.07$ (Gall and Neira, 2004) to $0.40 \pm 0.06$ (Neira et al., 2006) and this trait responds to early spawning selection. Traditional selection works well, with the phenotypic response to selection for early spawning fluctuating between $-2.74 \pm 0.7$ and $-3.23 \pm 1.3$ days per generation (Neira et al., 2006). However, phenotypic selection is still inefficient as it is impossible to impose selection directly on males. Furthermore, this phenotype is expressed during the reproductive age, at the end of the salmon's life. In this context, marker-assisted selection could increase the response to early or late spawning time selection in the short term.

Despite its importance as a Chilean farmed species, coho salmon remains poorly characterized from a genetic standpoint. In contrast to rainbow trout and Atlantic salmon (Salmo salar) (Davidson et al., 2010; Palti et al., 2011), the lack of a dense genetic map for this species has delayed the search for QTLs related to commercial and life-history traits (Araneda, 2005). Although a map has been published for coho salmon, it is based on an analysis of $48 \mathrm{~F}_{2}$ individuals and has low resolution, with only 133 co-dominant markers spanning $429.7 \mathrm{cM}$ in the female map (McClelland and Naish, 2008). This map has allowed the QTL mapping of minor effects for growth rate, length, weight and hatch- 
ing time (McClelland and Naish, 2010; O'Malley et al., 2010). Nevertheless, it is possible to use a comparative approach to discover new QTL by using genetic markers linked to QTL in closely-related species. This approach has been used to identify QTL associated with temperature tolerance in Arctic char (Salvelinus alpinus) (Somorjai et al., 2003a) based on previously-identified QTL from rainbow trout (Jackson et al., 1998; Perry et al., 2001).

The main aim of this study was to use a comparative approach to identify microsatellite loci associated with potential QTL that affect spawning time (SPT-QTL) in coho salmon; the microsatellites used are reportedly linked to this trait in rainbow trout. If the microsatellite markers linked to SPT-QTL in rainbow trout are conserved in coho salmon then we would expect to find strong allelic heterogeneity between populations under divergent selection for spawning time. Such heterogeneity would indicate an association between these microsatellite loci and SPT-QTL in coho salmon. The identification of loci linked to SPT-QTL should allow marker-assisted selection for spawning time in coho salmon.

\section{Materials and Methods}

\section{Experimental population and phenotypic evaluation}

The fish used in this study were reared in the Coho Breed Improvement Program facilities (Centro de Mejoramiento Genético) located in Coyhaique in southern Chile (S $45^{\circ} 34.422$ ' W $72^{\circ} 04.436$ ' W). The program started with two-year classes in 1992 and 1993, both of which were closed populations managed under a two-year reproductive cycle. The populations consisted of 30-35 males that were mated with 100-120 females in each cycle followed by selection for harvest weight and early spawning using an animal model (Winkler et al., 1999). In 1995, a divergent selection experiment was initiated using two sets of fish as breeders: those that spawned during the first third of the spawning season (40 females and 13 males, $N_{e}=39.2$; early spawning population) and those that spawned during the last third of the spawning season ( $40 \mathrm{fe}-$ males and 12 males, $N_{e}=36.9$; late spawning population). The effective size was held essentially constant for the next three generations $\left(N_{e} \approx 40\right)$ by mating $12-14$ males with 40 females (Araneda et al., 2009). Both populations were selected for three generations and spawning time was recorded as the number of days starting from December $31^{\text {st }}$ to the date of spawning for every season (Gall and Neira, 2004). In 2001, blood samples for DNA extraction were obtained from 20 females from the early spawning population and 20 females from the late spawning population. Additionally, DNA samples from 40 base population females were obtained from our sample bank. The average difference in spawning time between early and late populations in 2001 was 85 days (Araneda et al., 2009).

\section{Microsatellite loci and PCR conditions}

Nine microsatellite loci were used to screen for associations with spawning time (Table 1). Six and three microsatellite loci were previously identified as linked and unlinked with spawning time QTL (SPT-QTL) in rainbow

Table 1 - Primer sequences, annealing temperatures and SPT-QTL linkage evidence for nine microsatellite loci used in the QTL screening of female coho salmon selected from early and late spawning populations.

\begin{tabular}{|c|c|c|c|c|c|}
\hline Locus & Primer sequences $\left(5^{\prime}-3^{\prime}\right)$ & $\operatorname{Tm}\left({ }^{\circ} \mathrm{C}\right)$ & References & $\begin{array}{l}\text { Rainbow trout } \\
\text { linkage group* }\end{array}$ & $\begin{array}{l}\text { SPT-QTL linkage } \\
\text { status** }\end{array}$ \\
\hline OgolUW & $\begin{array}{l}\text { F: GATCTGGGCCTAAGGGAAAC } \\
\text { R: ACTAGCGGTTGGAGAACCC }\end{array}$ & 59 & Olsen et al. (1998) & RT3 & Linked \\
\hline Oki10 & $\begin{array}{l}\text { F: GGAGTGCTGGACAGATTGG } \\
\text { R: CAGCTTTTTACAAATCCTCCTG }\end{array}$ & $60-54^{\dagger}$ & Smith et al. (1998) & RT19 & Linked \\
\hline One $2 A S C$ & $\begin{array}{l}\text { F: GGTGCCAAGGTTCAGTTTATGTT } \\
\text { R: CAGGAATTTACAGGACCCAGGTT }\end{array}$ & 62 & Scribner et al. (1996) & RT24 & Linked \\
\hline Опен6 & $\begin{array}{l}\text { F: CAGAGTGGCCTAGATGCTTTAAT } \\
\text { R:CCACACACCAAATCCTACCCTTA }\end{array}$ & 60 & Scribner et al. (1996) & RT4 & Unlinked \\
\hline One19ASC & $\begin{array}{l}\text { F: CTGGAAAGCACAGAGAGAGCCTT } \\
\text { R: TCCAACAGTCTAACAGTCTAACCA }\end{array}$ & 57 & Scribner et al. (1996) & RT24 & Linked \\
\hline OmyFGT22TUF & $\begin{array}{l}\text { F: AGTGAACTCCAGTGTTCCGG } \\
\text { R: CTATGACGCGGCAGGAAC }\end{array}$ & $70-60^{\dagger}$ & Sakamoto (1996) & RT25 & Unlinked \\
\hline OmyFGT34TUF & $\begin{array}{l}\text { F: ACAGTAAGATGTGGGGGCTG } \\
\text { R: TAAATTGACTGAGCAGCTGCC }\end{array}$ & $64-58^{\dagger}$ & Sakamoto (1996) & RT19 & Linked \\
\hline Ots $4 B M L$ & $\begin{array}{l}\text { F: GACCCAGAGCACAGCACAA } \\
\text { R: GGAGGACACATTTCAGCAG }\end{array}$ & 58 & Banks et al. (1999) & RT24 & Linked \\
\hline OтуРиРиРуDU & $\begin{array}{l}\text { F: ATGCAGCGGATGTAGGGGGA } \\
\text { R: TTAAGTGAAAAGACGTAACTTACC }\end{array}$ & 58 & Morris et al. (1996) & RT24 & Unlinked \\
\hline
\end{tabular}

"Includes a "touchdown" profile of 8 cycles of -1.0 per cycle, prior to final annealing temperature. *According to Guyomard et al. (2006). **According to Sakamoto et al. (1999) and O’Malley et al. (2003). 
trout, respectively. Oki10 has never been used for SPTQTL mapping; however, it was considered to be QTLlinked because it is located in the rainbow trout RT19 linkage group, between One3ASC and OmyFGT34TUF. Oki10 is $10.3 \mathrm{cM}$ from OmyFGT34TUF (Guyomard et al., 2006) and $14.2 \mathrm{cM}$ from a SPT-QTL closely linked to OmyFGT34TUF (Sakamoto et al., 1999; O'Malley et al., 2003). For all descriptions of rainbow trout linkage groups we used the nomenclature proposed by Guyomard et al. (2006).

The forward primers used to amplify each locus were dye labeled and PCR amplicons were run on an automated sequencer (Model ABI377, Applied Biosystems) with GeneScan-500 ROX as the size standard. The thermal profile was $94{ }^{\circ} \mathrm{C}$ for $2 \mathrm{~min}$, followed by 30 cycles at $94{ }^{\circ} \mathrm{C}$ for $30 \mathrm{~s}, 57^{\circ} \mathrm{C}$ to $70{ }^{\circ} \mathrm{C}$ for $1 \mathrm{~min}$ (see Table 1 for the specific annealing temperature of each primer pair), $72{ }^{\circ} \mathrm{C}$ for $1 \mathrm{~min}$, and a final $5 \mathrm{~min}$ extension step at $72^{\circ} \mathrm{C}$. For some primer sets, we used a touchdown protocol to improve the PCR fragment resolution (Table 1). PCR was done in a total volume of $15 \mu \mathrm{L}$ containing $1.5 \mu \mathrm{L}$ of $10 \mathrm{x}$ PCR buffer, $4.0 \mu \mathrm{M}$ of each dNTP, $0.4 \mu \mathrm{M}$ of primer, $1.8 \mathrm{mM} \mathrm{MgCl}_{2}$, 0.5 units of $\mathrm{Taq}$ DNA polymerase (Invitrogen) and $40 \mathrm{ng}$ of DNA from each individual. DNA was extracted from blood samples using a phenol/chloroform protocol (Medrano et al., 1990) and quantified spectrophotometrically (Hewlett Packard model 8452A spectrophotometer).

\section{Association analysis}

Marker-trait associations were assessed using three statistical methods: (1) First, we applied the $L_{D}$ statistic, a multiple comparison approach based on contingency tables between microsatellite alleles and populations (Araneda $e t$ al., 2009; Colihueque et al., 2010). This procedure tests the null hypothesis that two populations are homogeneous with respect to the probability distribution of microsatellite al- leles; the alternative hypothesis is that at least one allele is excessively associated with a particular population (Choulakian and Mahdi, 2000). For every locus, the highest value of $L_{D}$ across alleles was compared to the chi-squared value, with one degree of freedom of 13.8 being equivalent to an LOD score of $3.0\left[Z \approx \chi^{2} / 2 \log (10)\right]$, which corresponded to an $\alpha$ level of approximately 0.0002 . (2) Second, we used an $\chi^{2}$ Monte-Carlo bootstrapping algorithm with 10,000 iterations to test allelic heterogeneity between populations (Zaykin and Pudovkin, 1993). (3) Finally, to assess genetic drift, we used a 99\% confidence interval (CI) for allelic frequency variance for a locus with two alleles in which:

$$
P\left[\left[\frac{(d . f .) \hat{S}^{2}}{\chi_{d . f, 1-\alpha / 2}^{2}}\right] \leq \sigma^{2} \leq\left[\frac{(d . f .) \hat{S}^{2}}{\chi_{d . f, \alpha / 2}^{2}}\right]\right]=1-\alpha
$$

using $\hat{S}=\sqrt{p q / 2 n_{e}}$ as an estimate of genetic drift, where $p$ is the frequency of the most frequent allele, $q$ is the pooled frequency of all other alleles, $\alpha=0.01$ and $N_{e}=37$ (the lowest value in our populations), so that d.f. was $2 N_{e}-1=73$. We also estimated the prediction of change by drift for the allele frequency with the highest $L_{D}$ value for every locus after three generations as: $p_{3}=p_{0}+3 \hat{S}$, where $p_{0}$ is the allele frequency in the base population (1995) and $p_{3}$ is the frequency of the same allele in 2001 (after three generations of selection).

\section{Results}

Table 2 shows a reduction in the number of alleles from 1995 to 2001 in nearly all of the loci sampled. This table also shows the range of allele sizes and the frequency of the most frequent allele across the three populations that were used to assess drift. The complete allele distributions and frequencies are shown in Tables S1 to S3 and the as-

Table 2 - Allelic characteristics of nine microsatellite loci in coho salmon females from base, early and late populations.

\begin{tabular}{|c|c|c|c|c|c|c|c|c|c|c|c|c|}
\hline \multirow[b]{2}{*}{ Locus } & \multicolumn{4}{|c|}{ Base (1995) } & \multicolumn{4}{|c|}{ Early (2001) } & \multicolumn{4}{|c|}{ Late (2001) } \\
\hline & $\begin{array}{l}\text { No. of } \\
\text { alleles }\end{array}$ & $\begin{array}{l}\text { Size } \\
\text { range } \\
(\mathrm{bp})\end{array}$ & $\begin{array}{c}\text { Most } \\
\text { frequent } \\
\text { allele }\end{array}$ & $\mathrm{p}$ & $\begin{array}{l}\text { No. of } \\
\text { alleles }\end{array}$ & $\begin{array}{l}\text { Size } \\
\text { range } \\
\text { (bp) }\end{array}$ & $\begin{array}{c}\text { Most } \\
\text { frequent } \\
\text { allele }\end{array}$ & $\mathrm{p}$ & $\begin{array}{l}\text { No. of } \\
\text { alleles }\end{array}$ & $\begin{array}{l}\text { Size } \\
\text { range } \\
\text { (bp) }\end{array}$ & $\begin{array}{l}\text { Most } \\
\text { frequent } \\
\text { allele }\end{array}$ & $\mathrm{p}$ \\
\hline OgolUW & 3 & $114-144$ & 122 & 0.5500 & 2 & $114-122$ & 114 & 0.6250 & 2 & $114-122$ & 114 & 0.5750 \\
\hline Oki10 & 18 & $113-243$ & 150 & 0.1500 & 11 & $125-243$ & 153 & 0.2750 & 9 & $125-231$ & 231 & 0.2750 \\
\hline One $2 A S C$ & 11 & $185-264$ & 210 & 0.3250 & 9 & $185-256$ & 202 & 0.2250 & 8 & $185-248$ & 242 & 0.3750 \\
\hline Onен6 & 11 & $269-325$ & 273 & 0.2051 & 10 & $259-311$ & 269 & 0.2750 & 6 & 269-299 & 275 & 0.2750 \\
\hline One19ASC & 7 & $222-240$ & 234 & 0.3125 & 6 & $222-240$ & 222 & 0.3500 & 5 & $226-236$ & 232 & 0.5000 \\
\hline OmyFGT22TUF & 13 & $211-262$ & 227 & 0.2125 & 8 & $219-262$ & 223 & 0.3250 & 11 & $207-262$ & $229 / 211$ & 0.1750 \\
\hline OmyFGT34TUF & 14 & $135-210$ & 153 & 0.1842 & 11 & $139-210$ & 185 & 0.2500 & 8 & $135-182$ & 143 & 0.4000 \\
\hline Ots $4 B M L$ & 4 & $134-140$ & 138 & 0.4000 & 4 & $134-140$ & 134 & 0.4000 & 3 & $134-140$ & 140 & 0.5750 \\
\hline ОтуРиРиРуDU & 9 & $385-430$ & 385 & 0.2895 & 7 & $385-430$ & 408 & 0.2500 & 9 & $134-424$ & 408 & 0.3000 \\
\hline
\end{tabular}

$\mathrm{p}$ : frequency of the most common allele. 
sessment of genetic drift is shown in Table S4 (all in Supplementary Material).

Six loci showed allelic heterogeneity among fish belonging to early and late spawning populations, which suggested that these loci could be associated with spawning time. Subsequent association analyses indicated that three loci (One2ASC, One19ASC and OmyFGT34TUF) were strongly associated with spawning time $(\mathrm{p}<0.0002)$ and a fourth locus, Oki10, was close to the limit of significance (Table 3). All four microsatellite loci that were possibly associated with spawning time showed differences in the allelic distribution of early and late spawning females compared to females from the base population (Figure 1). In particular, for OmyFGT34TUF, alleles 139 and 143 occurred at a high frequency in late spawning females $(32.5 \%$ and $40 \%$, respectively), but were infrequent in early spawning females (5\% and $2.5 \%$, respectively). On the same locus, allele 185 also occurred at a high frequency (25\%) and was found exclusively in early spawning females (Figure 1). Locus One2ASC had significantly higher allele 214 and 242 frequencies ( $30 \%$ and $37.5 \%$, respectively) in late spawning compared to early spawning females $(0 \%$ and 5\%, respectively), and locus One $19 A S C$ had a high frequency $(50 \%)$ of allele 232 in late spawning females compared to a frequency of only $10 \%$ in early spawning females (Figure 1). In early spawners, the latter locus also showed a high proportion (35\%) of an exclusive allele (222). Finally, locus Oki10 contained two alleles (223 and 231) exclusive to the late spawning group that both had high frequencies ( $20 \%$ and $27.5 \%$, respectively), while allele 129 (frequency of $20 \%$ ) was observed exclusively in the early spawning group (Figure 1).

The genetic drift effect estimated by using the most frequent allele in 1995 showed an average change in allele frequency of 5\% due to drift per generation, with an upper confidence interval (99\%CI) limit of 7.3\% (Table 4). The estimate of change due to drift, based on the allele frequency with the highest $L_{D}$ value, showed a drift effect that was always inferior to the change in gene frequency observed in 2001 for the three loci associated with spawning time (One2ASC, One19ASC and OmyFGT34TUF) and for Oki10. Thus, the frequency change expected due to drift was always inferior to the change observed after three generations of selection. For the other five loci, the change observed after selection was in the range of drift prediction (Table 4).

\section{Discussion}

Association analyses are always suspect because of the higher rate of false positives produced by spurious associations between phenotypes and non-causative marker loci. Such spurious associations can be produced by population subdivisions or genetic drift (Pritchard and Rosenberg, 1999). The reduction in the number of alleles from 1995 to 2001 was possibly a by-product of divergent selection for spawning time instead of a consequence of genetic drift. Our results indicated the association of three microsatellite loci (One2ASC, One19ASC and OmyFGT34TUF) with spawning time in coho salmon while a fourth locus (Oki10) had a suggestive association. In four loci the changes in allele frequencies were higher than expected by drift, which is consistent with a marker locus under co-selection with the QTL region. A similar pattern of co-selected markers linked to QTL has been shown for ethanol drinking in mice (Belknap et al., 1997) and such co-selection is proof of a true QTL (Abiola et al., 2003). As additional evidence, it should be noted that three of these loci were previously linked with QTL for the same trait in rainbow trout linkage groups RT24 and RT19 (Sakamoto et al., 1999; O'Malley et al., 2003). We have thus identified

Table 3 - Association analysis between eight microsatellite loci and spawning time in coho salmon females selected for early and late spawning time.

\begin{tabular}{|c|c|c|c|c|c|c|}
\hline Locus & $\chi^{2}$ & $\mathrm{p}^{\dagger}$ & $L_{D}$ & $\begin{array}{c}\text { Allele with highest } \\
L_{D} \text { value }\end{array}$ & $\mathrm{p}$ & LOD score ${ }^{\dagger \dagger}$ \\
\hline OgolUW & 0.208 & 0.8223 & 0.208 & 114 & 0.648077 & 0.05 \\
\hline Oki10 & 50.288 & $0.0000 *$ & 12.751 & 231 & 0.000355 & 2.77 \\
\hline One $2 A S C$ & 45.162 & $0.0000 *$ & 14.118 & 214 & $0.000170^{* *}$ & 3.07 \\
\hline Onен6 & 34.107 & $0.0001 *$ & 8.889 & 279 & 0.002869 & 1.93 \\
\hline One19ASC & 32.410 & $0.0000^{*}$ & 16.970 & 222 & $0.000038^{* *}$ & 3.68 \\
\hline OmyFGT22TUF & 29.649 & $0.0000^{*}$ & 7.679 & 211 & 0.005611 & 1.67 \\
\hline OmyFGT34TUF & 56.088 & $0.0000 *$ & 16.807 & 143 & $0.000041 * *$ & 3.65 \\
\hline Ots $4 B M L$ & 9.589 & $0.0109^{*}$ & 7.314 & 138 & 0.006841 & 0.89 \\
\hline OmyPuPuPyDU & 12.188 & 0.2115 & 5.164 & 385 & 0.023051 & 1.59 \\
\hline
\end{tabular}

"Estimated using a bootstrapping algorithm with the program CHIRXC (Zaykin and Pudovkin, 1993).

${ }^{\dagger}$ Approximate value estimated as $L_{D}$ value/4.6052.

*Indicates allelic heterogeneity.

**Indicates association with spawning date $(\mathrm{p}<0.0002$ or LOD score $>3.0)$. 
four SSR loci that are potentially useful in marker-assisted selection for early or late spawning time in coho salmon.

Our findings, along with previous evidence from QTL mapping in rainbow trout, support the presence of two
QTL regions that affect spawning time in coho salmon. The proposed position of both QTL is based on assumed synteny between the chromosomes of coho salmon and rainbow trout; this assumption suggests that these QTL
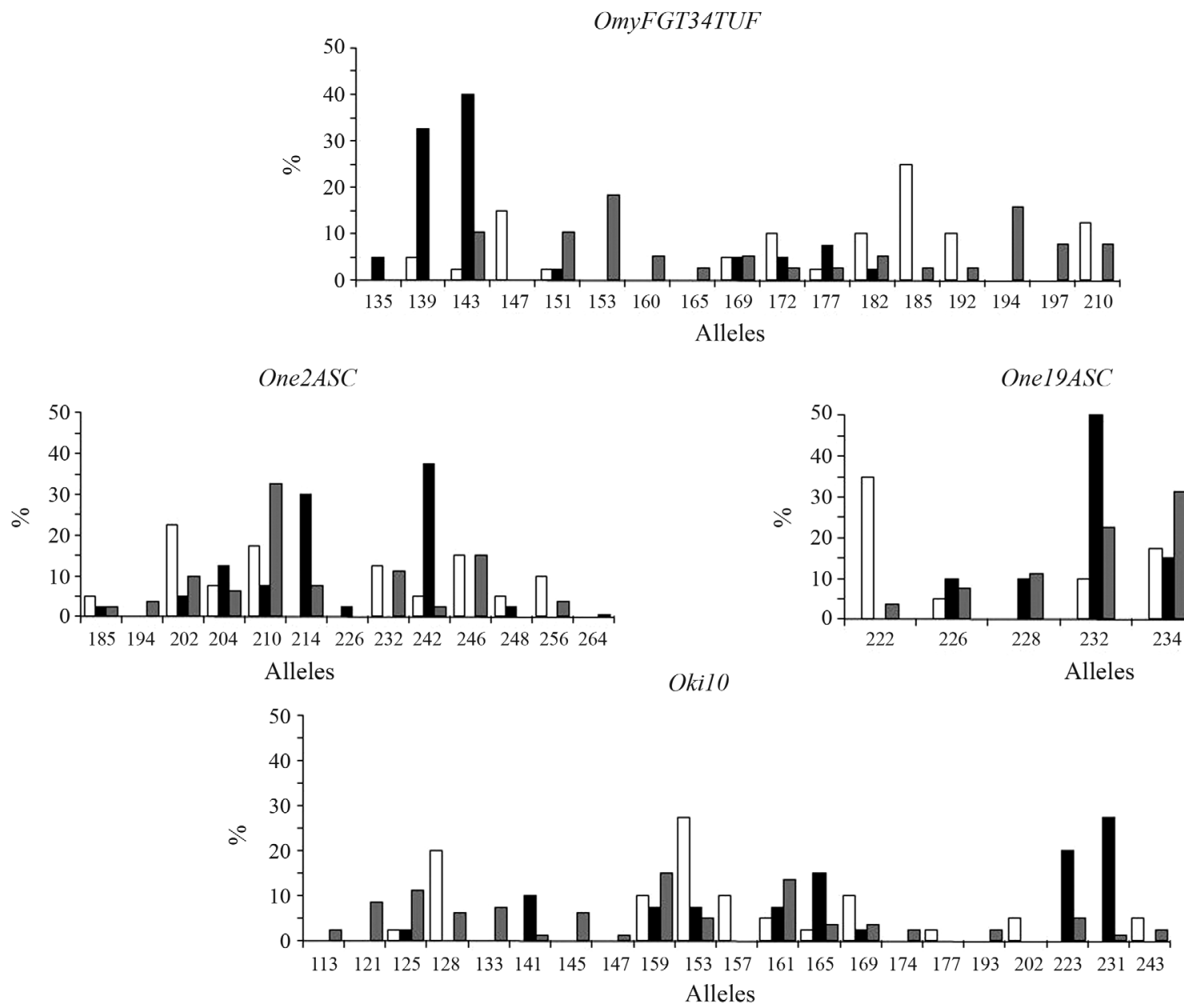

Figure 1 - Distribution of alleles in the four microsatellite loci of coho salmon showing the association with spawning date. White bars correspond to allelic frequencies for the early spawning population, black bars indicate allelic frequencies for the late spawning population and grey bars indicate allelic frequencies for the base population.

Table 4 - Change due to genetic drift predicted in alleles with the highest $L_{D}$ value relative to the initial frequency (base population) across all nine loci.

\begin{tabular}{lcccccc}
\hline Locus & $\begin{array}{c}\text { Estimated drift } \\
\text { in 1995 }\end{array}$ & $\begin{array}{c}\text { Drift 99\%CI } \\
1995\end{array}$ & $\begin{array}{c}\text { Allele with highest } \\
L_{D} \text { value }\end{array}$ & $\begin{array}{c}\text { Frequency in base } \\
\text { population in 1995 }\end{array}$ & $\begin{array}{c}\text { Maximum frequency Maximum frequency } \\
\text { observed in 2001 }\end{array}$ \\
expected by drift
\end{tabular}

E: Maximum frequency observed in the early population.

L: Maximum frequency observed in the late population. 
were present in ancestral genomes from which these species originated.

We hypothesize that one of these QTL is located close to the region bearing the loci One19ASC and One $2 A S C$ in a coho salmon linkage group syntenic with RT24 of rainbow trout. The RT24 linkage group of rainbow trout contains Ots $4 B L M$ and OmyPuPuPyDU, but these loci are located 23.5-24.5 cM from the pair One19ASC/One2ASC and, in agreement with our association analysis, they have never been linked with SPT-QTL (Sakamoto et al., 1999; O'Malley et al., 2003). The second QTL must be located in a linkage group syntenic to the rainbow trout linkage group RT19, in a region between Oki10 and OmyFGT34TUF, possibly near the latter locus. We expect that these putative SPT-QTL positions will be confirmed by formal linkage studies using these marker loci when coho salmon have a saturated genetic map.

Chromosome segment conservation among salmon species is being increasingly documented through the construction of genetic maps for salmonids and comparative genomic studies (Danzmann et al., 2005, 2008; Timusk et al., 2011). In addition, comparative QTL mapping is actively being undertaken for salmon species belonging to different genera. This approximation has been used to identify QTL for upper temperature tolerance among rainbow trout and Arctic char (Somorjai et al., 2003b), as well as for body weight and Fulton's condition factor among Oncorhynchus, Salvelinus and Salmo (Reid et al., 2005). Further evidence of synteny and conservation of the different priming sites for these microsatellites markers lies in the feasibility of using heterologous primers to amplify microsatellite loci across all salmon species (Araneda et al., 2008; Danzmann et al., 2008). Currently, all evidence obtained from comparative QTL mapping indicates that chromosome regions that affect the quantitative variation of several fitness-related traits in salmon, e.g., body weight, growth rate, spawning time and temperature tolerance, must have been present before the separation of lineages that gave rise to the modern salmonid species (O'Malley et al., 2003; Somorjai et al., 2003b; Reid et al., 2005).

\section{Acknowledgments}

We thank the staff of the Coho Breed Improvement Program, especially Alejandro Alert, Rodrigo Manterola, Jean Paul Lhorente, Claudio Urrejola and Carlos Soto, for collecting data and managing the fish populations. We are especially grateful to Roberto Neira for assistance in obtaining historical records of spawning times for the early and late coho populations. This work was supported by grants from FIA (BIOT-01-AC-21) and FONDAP OBM Peces.

\section{References}

Abiola O, Angel J, Avner P, Bachmanov AA, Belknap JK, Bennett B, Blankenhorn EP, Blizard DA, Bolivar V, Brockmann
GA et al. (2003) The nature and identification of quantitative trait loci: A community's view. Nat Rev Genet 4:911916.

Araneda C (2005) Actualización de los mapas genéticos en salmones. Avan Prod Anim 30:15-18.

Araneda C, Neira R, Lam N and Iturra P (2008) Salmonids. In: Kocher T and Kole C (eds) Genome Mapping and Genomics in Fishes and Aquatic Animals. Springer Verlag, Berlin, pp 1-43.

Araneda C, Lam N, Díaz NF, Cortez S, Pérez C, Neira R and Iturra $\mathrm{P}$ (2009) Identification, development, and characterization of three molecular markers associated to spawning date in Coho salmon (Oncorhynchus kisutch). Aquaculture 296:21-26.

Belknap JK, Richards SP, O’Toole LA, Helms ML and Phillips TJ (1997) Short-term selective breeding as a tool for QTL mapping: Ethanol preference drinking in mice. Behav Genet 27:55-66.

Choulakian V and Mahdi S (2000) A new statistic for the analysis of association between trait and polymorphic marker loci. Math Biosci 164:139-145.

Colihueque N, Cardenas R, Ramirez L, Estay F and Araneda C (2010) Analysis of the association between spawning time QTL markers and the biannual spawning behavior in rainbow trout (Oncorhynchus mykiss). Genet Mol Biol 33:578582.

Danzmann RG, Cairney M, Davidson WS, Ferguson MM, Gharbi K, Guyomard R, Holm LE, Leder E, Okamoto N and Ozaki A (2005) A comparative analysis of the rainbow trout genome with 2 other species of fish (Arctic charr and Atlantic salmon) within the tetraploid derivative Salmonidae family (subfamily, Salmoninae). Genomics 48:1037-1051.

Danzmann R, Davidson E, Ferguson M, Gharbi K, Koop B, Hoyheim B, Lien S, Lubieniecki K, Moghadam H, Park J et al. (2008) Distribution of ancestral proto-actinopterygian chromosome arms within the genomes of 4R-derivative salmonid fishes (Rainbow trout and Atlantic salmon). BMC Genomics 9:e557.

Davidson W, Koop B, Jones S, Iturra P, Vidal R, Maass A, Jonassen I, Lien S and Omholt S (2010) Sequencing the genome of the Atlantic salmon (Salmo salar). Genome Biol 11:e403.

Fishback AG, Danzmann RG and Ferguson MM (2000) Microsatellite allelic heterogeneity among hatchery rainbow trout maturing in different seasons. J Fish Biol 57:1367-1380.

Gall GAE and Neira R (2004) Genetic analysis of female reproduction traits of farmed coho salmon (Oncorhyncus kisutch). Aquaculture 234:143-154.

Guyomard R, Mauger S, Tabet-Canale K, Martineau S, Genet C, Krieg F and Quillet E (2006) A Type I and Type II microsatellite linkage map of rainbow trout (Oncorhynchus mykiss) with presumptive coverage of all chromosome arms. BMC Genomics 7:e302.

Jackson TR, Ferguson MM, Danzmann RG, Fishback AG, Ihssen PE, O'Connell M and Crease TJ (1998) Identification of two QTL influencing upper temperature tolerance in three rainbow trout (Oncorhynchus mykiss) half-sib families. Heredity 80:143-151.

Leder EH, Danzmann RG and Ferguson MM (2006) The candidate gene, clock, localizes to a strong spawning time quantitative trait locus region in rainbow trout. J Hered 97:74-80. 
McClelland EK and Naish KA (2008) A genetic linkage map for coho salmon (Oncorhynchus kisutch). Anim Genet 39:169179.

McClelland EK and Naish KA (2010) Quantitative trait locus analysis of hatch timing, weight, length and growth rate in coho salmon, Oncorhynchus kisutch. Heredity 105:562-573.

Medrano JF, Aasen E and Sharrow L (1990) DNA extraction from nucleated red-blood cells. Biotechniques 8:43-43.

Neira R, Díaz NF, Gall GAE, Gallardo JA, Lhorente JP and Alert A (2006) Genetic improvement in coho salmon (Oncorhynchus kisutch). II: Selection response for early spawning date. Aquaculture 257:1-8.

O'Malley KG, Sakamoto T, Danzmann RG and Ferguson MM (2003) Quantitative trait loci for spawning date and body weight in rainbow trout: Testing for conserved effects across ancestrally duplicated chromosomes. J Hered 94:273-284.

O'Malley KG, McClelland EK and Naish KA (2010) Clock genes localize to quantitative trait loci for stage-specific growth in juvenile coho salmon, Oncorhynchus kisutch. J Hered 101:628-632.

Palti Y, Genet C, Luo M-C, Charlet A, Gao G, Hu Y, CastanoSanchez C, Tabet-Canale K, Krieg F, Yao J et al. (2011) A first generation integrated map of the rainbow trout genome. BMC Genomics 12:e180.

Perry GML, Danzmann RG, Ferguson MM and Gibson JP (2001) Quantitative trait loci for upper thermal tolerance inoutbred strains of rainbow trout (Oncorhynchus mykiss). Heredity 86:333-341.

Pritchard JK and Rosenberg NA (1999) Use of unlinked genetic markers to detect population stratification in association studies. Am J Hum Genet 65:220-228.

Quinn TP, Peterson JA, Gallucci VF, Hershberger WK and Brannon EL (2002) Artificial selection and environmental change: Countervailing factors affecting the timing of spawning by coho and chinook salmon. Trans Am Fish Soc 131:591598.

Reid DP, Szanto A, Glebe B, Danzmann RG and Ferguson MM (2005) QTL for body weight and condition factor in Atlantic salmon (Salmo salar): Comparative analysis with rainbow trout (Onchorhynhus mykiss) and Artic charr (Salvelinus alpinus). Heredity 94:166-172.

Sakamoto T (1996) Study for the Introduction of Positional Cloning Method Using DNA Markers in Fisheries Science. PhD Thesis, Department of Aquatic Biosciences, Tokyo University of Fisheries, Tokyo.

Sakamoto T, Danzmann RG, Okamoto N, Ferguson MM and Ihssen PE (1999) Linkage analysis of quantitative trait loci associated with spawning time in rainbow trout (Oncorhynchus mykiss). Aquaculture 173:33-43.

Siitonen L and Gall GAE (1989) Response to selection for early spawn date in rainbow trout, Salmo gairdneri. Aquaculture 78:153-161.

Somorjai IML, Danzmann RG and Ferguson MM (2003a) Distribution of temperature tolerance quantitative trait loci in Arctic charr (Salvelinus alpinus) and inferred homologies in rainbow trout (Oncorhynchus mykiss). Genetics 165:14431456.

Somorjai IML, Danzmann RG and Ferguson MM (2003b) Distribution of temperature tolerance quantitative trait loci in arctic charr (Salvelinus alpinus) and inferred homologies in rainbow trout (Oncorhynchus mykiss). Genetics:1443-1456.

Su G-S, Liljedahl L-E and Gall GAE (1999) Estimates of phenotypic and genetic parameters for within-season date and age at spawning of female rainbow trout. Aquaculture 171:209220.

Timusk E, Ferguson M, Moghadam H, Norman J, Wilson C and Danzmann R (2011) Genome evolution in the fish family Salmonidae: Generation of a brook charr genetic map and comparisons among charrs (Arctic charr and brook charr) with rainbow trout. BMC Genetics 12:e68.

Winkler FM, Bartley D and Díaz NF (1999) Genetic differences among year classes in a hatchery population of coho salmon (Oncorhynchus kisutch (Walbaum, 1792)) in Chile. Aquaculture 173:425-433.

Zaykin DV and Pudovkin AI (1993) Two programs to estimate significance of $\chi^{2}$ values using pseudo-probability tests. J Hered 84:152.

\section{Supplementary Material}

The following online material is available for this article:

Table S1 - Allele frequencies in the base population

Table S2 - Allele frequencies in the early spawning population

Table S3 - Allele frequencies in the late spawning population

Table S4 - Assessment of the influence of genetic drift

This material is available as part of the online article from http://www.scielo.br/gmb.

Associate Editor: Antonio Matteo Solé-Cava

License information: This is an open-access article distributed under the terms of the Creative Commons Attribution License, which permits unrestricted use, distribution, and reproduction in any medium, provided the original work is properly cited. 
Table S1 - Allele frequencies in the base population (1995).

\begin{tabular}{|c|c|c|c|c|c|c|c|c|c|c|c|c|c|}
\hline & ne2ASC & & & Dne $\mu 6$ & & On & e19ASC & & & go1UW & & Omy & FGT22TUF \\
\hline Allelles & Frequencies & & Allelles & Frequencies & & Allelles & Frequencies & & Allelles & Frequencies & & Allelles & Frequencies \\
\hline 185 & 0.0250 & 1 & 269 & 0.0769 & 1 & 222 & 0.0375 & 1 & 114 & 0.43750 & 1 & 211 & 0.0375 \\
\hline 194 & 0.0375 & 2 & 273 & 0.2051 & 2 & 226 & 0.0750 & 2 & 122 & 0.55000 & 2 & 219 & 0.0250 \\
\hline 202 & 0.1000 & 3 & 275 & 0.1154 & 3 & 228 & 0.1125 & 3 & 144 & 0.01250 & 3 & 223 & 0.2125 \\
\hline 204 & 0.0625 & 4 & 279 & 0.1026 & 4 & 232 & 0.2250 & 4 & & & 4 & 225 & 0.0375 \\
\hline 210 & 0.3250 & 5 & 283 & 0.0769 & 5 & 234 & 0.3125 & 5 & & & 5 & 227 & 0.2125 \\
\hline 214 & 0.0750 & 6 & 287 & 0.0897 & 6 & 236 & 0.1625 & 6 & & & 6 & 229 & 0.0375 \\
\hline 232 & 0.1125 & 7 & 291 & 0.0513 & 7 & 240 & 0.0750 & 7 & & & 7 & 231 & 0.1000 \\
\hline 242 & 0.0250 & 8 & 299 & 0.0769 & 8 & & & 8 & & & 8 & 234 & 0.0250 \\
\hline 246 & 0.1500 & 9 & 305 & 0.0897 & 9 & & & 9 & & & 9 & 238 & 0.0750 \\
\hline 256 & 0.0375 & 0 & 308 & 0.0769 & 0 & & & 0 & & & 0 & 240 & 0.0500 \\
\hline 264 & 0.0500 & 1 & 325 & 0.0385 & 1 & & & 1 & & & 1 & 246 & 0.0375 \\
\hline & & 2 & & & 2 & & & 2 & & & 2 & 254 & 0.1000 \\
\hline & & 3 & & & 3 & & & 3 & & & 3 & 262 & 0.0500 \\
\hline 12 & & & 11 & & & 7 & & & 3 & & & 13 & \\
\hline
\end{tabular}

\begin{tabular}{|c|c|c|c|c|c|c|c|c|c|c|}
\hline \multirow{2}{*}{\multicolumn{2}{|c|}{\begin{tabular}{|c|} 
Oki10 \\
Allelles
\end{tabular}}} & & \multicolumn{2}{|c|}{ OmyFGT34TUF } & & \multicolumn{2}{|c|}{ Ots4UW } & & \multicolumn{2}{|c|}{ OmyPuPuPyDU } \\
\hline & & & Allelles & Frequencies & & Allelles & Frequencies & & Allelles & Frequencies \\
\hline 113 & 0.0250 & 1 & 143 & 0.1053 & 1 & 134 & 0.1875 & 1 & 385 & 0.2895 \\
\hline 121 & 0.0875 & 2 & 151 & 0.1053 & 2 & 136 & 0.0500 & 2 & 388 & 0.0789 \\
\hline 125 & 0.1125 & 3 & 153 & 0.1842 & 3 & 138 & 0.4000 & 3 & 393 & 0.0921 \\
\hline 129 & 0.0625 & 4 & 160 & 0.0526 & 4 & 140 & 0.3625 & 4 & 399 & 0.0526 \\
\hline 133 & 0.0750 & 5 & 165 & 0.0263 & 5 & & & 5 & 405 & 0.1316 \\
\hline 141 & 0.0125 & 6 & 169 & 0.0526 & 6 & & & 6 & 408 & 0.1842 \\
\hline 145 & 0.0625 & 7 & 172 & 0.0263 & 7 & & & 7 & 410 & 0.0395 \\
\hline 147 & 0.0125 & 8 & 177 & 0.0263 & 8 & & & 8 & 421 & 0.1053 \\
\hline 150 & 0.1500 & 9 & 182 & 0.0526 & 9 & & & 9 & 430 & 0.0263 \\
\hline 153 & 0.0500 & 0 & 185 & 0.0263 & 0 & & & 0 & & \\
\hline 161 & 0.1375 & 1 & 192 & 0.0263 & 1 & & & 1 & & \\
\hline 165 & 0.0375 & 2 & 194 & 0.1579 & 2 & & & 2 & & \\
\hline 169 & 0.0375 & 3 & 197 & 0.0789 & 3 & & & 3 & & \\
\hline 174 & 0.0250 & 4 & 210 & 0.0789 & 4 & & & 4 & & \\
\hline 193 & 0.0250 & 5 & & & 5 & & & 5 & & \\
\hline 223 & 0.0500 & 6 & & & 6 & & & 6 & & \\
\hline 231 & 0.0125 & 7 & & & 7 & & & 7 & & \\
\hline 243 & 0.0250 & 8 & & & 8 & & & 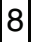 & & \\
\hline
\end{tabular}


Table S2 - Allele frequencies in the early spawning population (2001).

\begin{tabular}{|c|c|c|c|c|c|c|c|c|c|c|c|c|c|}
\hline \multicolumn{2}{|c|}{ One2ASC } & & \multicolumn{2}{|c|}{ One $\mu 6$} & & \multicolumn{2}{|c|}{ One19ASC } & & \multicolumn{2}{|c|}{ Ogo1UW } & & \multicolumn{2}{|c|}{ OmyFGT22TUF } \\
\hline Allelles & Frequencies & & Allelles & Frequencies & & Allelles & Frequencies & & Allelles & Frequencies & & Allelles & Frequencies \\
\hline 185 & 0.0500 & 1 & 259 & 0.1000 & 1 & 222 & 0.3500 & 1 & 114 & 0.62500 & 1 & 219 & 0.2250 \\
\hline 202 & 0.2250 & 2 & 269 & 0.2750 & 2 & 226 & 0.0500 & 2 & 122 & 0.37500 & 2 & 223 & 0.3250 \\
\hline 204 & 0.0750 & 3 & 273 & 0.1500 & 3 & 232 & 0.1000 & 3 & & & 3 & 227 & 0.0500 \\
\hline 210 & 0.1750 & 4 & 275 & 0.1250 & 4 & 234 & 0.1750 & 4 & & & 4 & 229 & 0.0500 \\
\hline 232 & 0.1250 & 5 & 283 & 0.0750 & 5 & 236 & 0.3000 & 5 & & & 5 & 231 & 0.2000 \\
\hline 242 & 0.0500 & 6 & 287 & 0.0250 & 6 & 240 & 0.0250 & 6 & & & 6 & 240 & 0.0500 \\
\hline 246 & 0.1500 & 7 & 291 & 0.1250 & 7 & & & 7 & & & 7 & 246 & 0.0750 \\
\hline 248 & 0.0500 & 8 & 299 & 0.0250 & 8 & & & 8 & & & 8 & 262 & 0.0250 \\
\hline 256 & 0.1000 & 9 & 305 & 0.0500 & 9 & & & 9 & & & 9 & & \\
\hline & & 0 & 311 & 0.0500 & 0 & & & 0 & & & 0 & & \\
\hline 9 & & $\begin{array}{l}1 \\
2\end{array}$ & 10 & & $\begin{array}{l}1 \\
2\end{array}$ & 6 & & 2 & 2 & & 2 & 8 & \\
\hline
\end{tabular}

\begin{tabular}{|c|c|c|c|c|c|c|c|c|}
\hline \multicolumn{2}{|r|}{ Oki10 } & \multicolumn{2}{|c|}{ OmyFGT34TUF } & & \multicolumn{2}{|c|}{ Ots4BML } & \multicolumn{2}{|c|}{ OmyPuPuPyDU } \\
\hline Allelles & Frequencies & Allelles & Frequencies & & Allelles & Frequencies & Allelles & Frequencies \\
\hline 125 & 0.0250 & $1 \longdiv { 1 3 9 }$ & 0.0500 & 1 & 134 & 0.4000 & $1 \longdiv { 3 8 5 }$ & 0.2250 \\
\hline 129 & 0.2000 & 143 & 0.0250 & 2 & 136 & 0.0250 & 388 & 0.1000 \\
\hline 150 & 0.1000 & 147 & 0.1500 & 3 & 138 & 0.2250 & 393 & 0.1750 \\
\hline 153 & 0.2750 & 151 & 0.0250 & 4 & 140 & 0.3500 & 408 & 0.2500 \\
\hline 157 & 0.1000 & 169 & 0.0500 & 5 & & & 410 & 0.0250 \\
\hline 161 & 0.0500 & 172 & 0.1000 & 6 & & & 421 & 0.1500 \\
\hline 165 & 0.0250 & 177 & 0.0250 & 7 & & & 430 & 0.0750 \\
\hline 169 & 0.1000 & 182 & 0.1000 & 8 & & & 8 & \\
\hline 177 & 0.0250 & 185 & 0.2500 & 9 & & & 9 & \\
\hline 202 & 0.0500 & 192 & 0.1000 & 0 & & & 0 & \\
\hline 243 & 0.0500 & 210 & 0.1250 & 1 & & & 1 & \\
\hline 11 & & $\begin{array}{l}2 \\
3\end{array}$ & & $\begin{array}{l}2 \\
3\end{array}$ & 4 & & 7 & \\
\hline
\end{tabular}


Table S3 - Allele frequencies in the late spawning population (2001).

\begin{tabular}{|c|c|c|c|c|c|c|c|c|c|c|c|c|c|}
\hline \multicolumn{2}{|c|}{ One2ASC } & & \multicolumn{2}{|c|}{ One $\mu 6$} & & \multicolumn{2}{|c|}{ One19ASC } & & \multicolumn{2}{|c|}{ Ogo1UW } & & \multicolumn{2}{|c|}{ OmyFGT22TUF } \\
\hline Allelles & Frequencies & & Allelles & Frequencies & & Allelles & Frequencies & & Allelles & Frequencies & & Allelles & Frequencies \\
\hline 185 & 0.0250 & 1 & 269 & 0.2250 & 1 & 226 & 0.1000 & & 114 & 0.5750 & 1 & 207 & 0.0500 \\
\hline 202 & 0.0500 & 2 & 275 & 0.2750 & 2 & 228 & 0.1000 & & 122 & 0.4250 & 2 & 211 & 0.1750 \\
\hline 204 & 0.1250 & 3 & 279 & 0.2000 & 3 & 232 & 0.5000 & & & & 3 & 219 & 0.0250 \\
\hline 210 & 0.0750 & 4 & 287 & 0.1500 & 4 & 234 & 0.1500 & & & & 4 & 223 & 0.1500 \\
\hline 214 & 0.3000 & 5 & 291 & 0.0500 & 5 & 236 & 0.1500 & & & & 5 & 227 & 0.1250 \\
\hline 226 & 0.0250 & 6 & 299 & 0.1000 & 6 & & & & & & 6 & 229 & 0.1750 \\
\hline 242 & 0.3750 & 7 & & & 7 & & & & & & 7 & 231 & 0.0750 \\
\hline 248 & 0.0250 & 8 & & & 8 & & & & & & 8 & 240 & 0.0500 \\
\hline & & 9 & & & 9 & & & & & & 9 & 246 & 0.0250 \\
\hline & & 0 & & & 0 & & & & & & 0 & 256 & 0.1000 \\
\hline & & 1 & & & 1 & & & & & & 1 & 262 & 0.0500 \\
\hline 8 & & 3 & 6 & & 3 & 5 & & & 2 & & 3 & 11 & \\
\hline
\end{tabular}

\begin{tabular}{|c|c|c|c|c|c|c|c|c|c|c|}
\hline \multicolumn{2}{|r|}{ Oki10 } & & \multicolumn{3}{|c|}{ OmyFGT34TUF } & \multicolumn{2}{|c|}{ Ots4UW } & \multicolumn{3}{|c|}{ OmyPuPuPyDU } \\
\hline Allelles & Frequencies & & Allelles & Frequencies & & Allelles & Frequencies & & Allelles & Frequencies \\
\hline 125 & 0.0250 & 1 & 135 & 0.0500 & 1 & 134 & 0.4000 & 1 & 134 & 0.0250 \\
\hline 141 & 0.1000 & 2 & 139 & 0.3250 & 2 & 138 & 0.0250 & 2 & 140 & 0.0250 \\
\hline 150 & 0.0750 & 3 & 143 & 0.4000 & 3 & 140 & 0.5750 & 3 & 385 & 0.0500 \\
\hline 153 & 0.0750 & 4 & 151 & 0.0250 & 4 & & & 4 & 388 & 0.1750 \\
\hline 161 & 0.0750 & 5 & 169 & 0.0500 & 5 & & & 5 & 393 & 0.1250 \\
\hline 165 & 0.1500 & 6 & 172 & 0.0500 & 6 & & & 6 & 405 & 0.0250 \\
\hline 169 & 0.0250 & 7 & 177 & 0.0750 & 7 & & & 7 & 408 & 0.3000 \\
\hline 223 & 0.2000 & 8 & 182 & 0.0250 & 8 & & & 8 & 421 & 0.1000 \\
\hline 231 & 0.2750 & 9 & & & 9 & & & 9 & 424 & 0.0250 \\
\hline & & & & & & & & & 430 & 0.1500 \\
\hline 9 & & $\begin{array}{l}1 \\
2\end{array}$ & 8 & & $\begin{array}{l}1 \\
2\end{array}$ & 3 & & $\begin{array}{l}1 \\
2\end{array}$ & 10 & \\
\hline
\end{tabular}


Table S4 - Assessment of the effect of genetic drift.

The approximate genetic drift was estimated in a simple way by using the formula for a locus with two alleles $S=p q / s q r t(2 \mathrm{Ne})$,

where $\mathrm{Ne}=37$ was applied because this was the lowest value in our populations and the harmonic means across three generations

must be close to this value. The confidence intervals (Lower lim and Upper lim) for S (drift) were estimated from the $\mathrm{Cl}$ of the variance.

Drift was estimated using as $p$ the frequency from the most frequent allele in 1995 and $q=1-p$.

\begin{tabular}{|r|c|c|c|ccc|}
\hline \multicolumn{1}{|l|}{ Locus } & $\mathbf{p}$ & $\mathbf{S}=\mathbf{d r i f t}$ & $\boldsymbol{S}^{\mathbf{2}}$ & Lower Lim & Drift & Upper Lim \\
\hline Ogo1UW & 0.5500 & 0.05783 & 0.0033446 & 0.0046 & $\leq S \leq$ & 0.0731 \\
Oki10 & 0.1500 & 0.04151 & 0.0017230 & 0.0033 & $\leq \mathrm{S} \leq$ & 0.0525 \\
One2ASC & 0.3250 & 0.05445 & 0.0029645 & 0.0043 & $\leq \mathrm{S} \leq$ & 0.0689 \\
One $\boldsymbol{\mu}$ 6 & 0.2051 & 0.04694 & 0.0022032 & 0.0037 & $\leq \mathrm{S} \leq$ & 0.0594 \\
One19ASC & 0.3125 & 0.05388 & 0.0029033 & 0.0043 & $\leq \mathrm{S} \leq$ & 0.0682 \\
OmyFGT22TUF & 0.2125 & 0.04755 & 0.0022614 & 0.0038 & $\leq \mathrm{S} \leq$ & 0.0601 \\
OmyFGT34TUF & 0.1842 & 0.04506 & 0.0020307 & 0.0036 & $\leq \mathrm{S} \leq$ & 0.0570 \\
Ots4BML & 0.4000 & 0.05695 & 0.0032432 & 0.0045 & $\leq \mathrm{S} \leq$ & 0.0720 \\
OmyPuPuPyDU & 0.2895 & 0.05272 & 0.0027796 & 0.0042 & $\leq \mathrm{S} \leq$ & 0.0667 \\
\hline Mean & 0.05052 & 0.0025521 & 0.0040 & $\leq \mathrm{S} \leq$ & 0.0639
\end{tabular}

$g l=2 \mathrm{Ne}-1=$

$X^{2}(0.995)=\quad 45.629$

$X^{2}(0.005)=\quad 107.862$

Drift was estimated using as $p$ the frequency in 1995 from the allele with the highest LD value of the two 2001 populations.

\begin{tabular}{|c|c|c|c|c|c|c|c|c|}
\hline \multirow[b]{2}{*}{ Locus } & \multirow[b]{2}{*}{ Allele } & \multirow{2}{*}{$\begin{array}{c}\text { Initial frequency } \\
\text { in } 1995\end{array}$} & \multicolumn{3}{|c|}{ Frequencies observed after 3 generations } & \multicolumn{2}{|c|}{ Change by drift after 3 generations } & \multirow[b]{2}{*}{ Dif O-E Max † } \\
\hline & & & drift $=\mathbf{S}$ & 2001_Early & 2001_Late & Min Freq. & Max Freq. & \\
\hline Ogo1UW & 114 & 0.4375 & 0.0577 & 0.6250 & 0.5750 & 0.2645 & 0.6105 & 0.0145 \\
\hline Oki10 & 231 & 0.0125 & 0.0129 & 0.0000 & 0.2750 & -0.0262 & 0.0512 & 0.2238 \\
\hline One2ASC & 214 & 0.0750 & 0.0306 & 0.0000 & 0.3000 & -0.0169 & 0.1669 & 0.1331 \\
\hline One $\mu 6$ & 279 & 0.1026 & 0.0353 & 0.0000 & 0.2000 & -0.0032 & 0.2084 & -0.0084 \\
\hline One19ASC & 222 & 0.0375 & 0.0221 & 0.3500 & 0.0000 & -0.0288 & 0.1038 & 0.2462 \\
\hline OmyFGT22TUF & 211 & 0.0375 & 0.0221 & 0.0000 & 0.1750 & -0.0288 & 0.1038 & 0.0712 \\
\hline OmyFGT34TUF & 143 & 0.1053 & 0.0357 & 0.0250 & 0.4000 & -0.0017 & 0.2123 & 0.1877 \\
\hline Ots4BML & 138 & 0.4000 & 0.0569 & 0.2250 & 0.0250 & 0.2292 & 0.5708 & -0.3458 \\
\hline OmyPuPuPyDU & 385 & 0.2895 & 0.0527 & 0.2250 & 0.0500 & 0.1313 & 0.4477 & -0.2227 \\
\hline
\end{tabular}

† Maximum differences between observed and expected (by drift) alleles frequencies.

\begin{tabular}{|r|c|c|c|}
\hline \multicolumn{1}{|l|}{ Locus } & Allele & $\begin{array}{c}\text { Allele with highest } \\
\text { LD }\end{array}$ & Most freq. allele \\
\hline Ogo1UW & 114 & 0.0145 & 0.0140 \\
Oki10 & 231 & $\mathbf{0 . 2 2 3 8}$ & $\mathbf{0 . 1 3 8 0}$ \\
One2ASC & 214 & $\mathbf{0 . 1 3 3 1}$ & $\mathbf{0 . 0 6 1 7}$ \\
One $\boldsymbol{\mu}$ 6 & 279 & -0.0084 & -0.0434 \\
One19ASC & 222 & 0.2462 & $\mathbf{0 . 1 5 0 9}$ \\
OmyFGT22TUF & 211 & 0.0712 & -0.0052 \\
OmyFGT34TUF & 143 & 0.1877 & $\mathbf{0 . 1 5 9 5}$ \\
Ots4BML & 138 & -0.3458 & -0.3458 \\
OmyPuPuPyDU & 385 & -0.2227 & -0.2227 \\
\hline
\end{tabular}

